\title{
Pregnancy Outcomes in Patients with Heart Valve Replacement: Sohag Perspective Ahmed Mohammed Ahmed Mohammed ${ }^{1}$, Mohammed Sabry Ebrahem ${ }^{1}$, Ayman Mohammed Mohammed ${ }^{2}$, Khaled Mohammed Abdelal' ${ }^{2}$, Hazem Mohammed Mohammed ${ }^{1}$, Mostafa Abd Elkhalek Abdellah ${ }^{1}$ Departments of ${ }^{1}$ Obstetrics and Gynecology and ${ }^{2}$ Cardiothoracic Surgery, Faculty of Medicine - Sohag University, Egypt \\ *Corresponding author: Ahmed Mohammed Ahmed Mohammed, Mobile: (+20)01092200298. Email: dr_ahmedhammad62@yahoo.com.
}

\begin{abstract}
Background: Management of a pregnant woman with a prosthetic heart valve requires significant contemplations, particularly concerning looking after anticoagulation.

Objective: We directed this observational study to notice maternal and fetal results in pregnant women with heart valve replacement in Sohag University Hospital.

Patients and methods: An observational study was done in Sohag University Hospital, 20 cases recruited in Department of Obstetrics and Gynecology during the period from April 2019 to October 2019. All cases were exposed to finish history taking, total physical assessment (general and obstetrical), obstetric US and investigations as echocardiography, PT, PC and INR.

Results: The mean age of the study group was around 28 years, with a range from 18 to 38 years. The vast majority of the cases had mitral valve replaced. CS was done for $40 \%$ of the cases, followed by vaginal delivery in $35 \%$ of them, evacuation in $20 \%$ and hysterotomy in one case (5\%). Hemorrhagic complications were seen in $25 \%$ of the cases, followed by thrombosis and rapid $\mathrm{AF}(10 \%$ each), then heart failure and supraventricular arrhythmias ( $5 \%$ each). Miscarriage before the $24^{\text {th }}$ week occurred in $30 \%$ of the cases and IUFD in one case (5\%). Before 14 weeks of gestation, most of the cases used heparin either UFH or LMWH, with only $35 \%$ used vitamin K antagonists. Hemorrhage was more common with MVR.
\end{abstract}

Conclusion: Patients with mechanical valves have more rate of fetal misfortunes and maternal complexities. Mitral valve replacement is related with more maternal hemorrhagic complications than aortic valve alone or double valve substitution.

Keywords: Pregnancy Outcome, Heart Valve Replacement.

\section{INTRODUCTION}

Physiologic adaptations are found in pregnancy to optimize fetal growth and development. The major cardiovascular hemodynamic changes seen in pregnancy include increased cardiac output, expanded blood volume, and reduced systemic vascular resistance and blood pressure. Increased preload (due to the expansion of the blood volume), decreased afterload (due to the decreased systemic vascular resistance), and increased maternal heart rate all lead to increased cardiac output and workload (1).

In pregnancy, there is critical change in coagulation system contrasted with non-pregnant women such as increased concentrations of fibrinogen, coagulation factors VII, VIII, IX, X, XII and VWF and decreased proteins $\mathrm{C}$ and $\mathrm{S}$ levels. Pregnancy in a woman with a mechanical heart valve is associated with high maternal and fetal complications. In women with mechanical valves, pregnancy is associated with a very high risk of complications (modified WHO risk classification III). A poor maternal outcome was defined as maternal mortality or serious illness - admission to intensive care for more than one day, valve thrombosis or valve malfunction resulting in heart failure, cerebrovascular disease, or bleeding disorders requiring transfusion or return to theatre (primary postpartum hemorrhage, secondary postpartum hemorrhage, internal bleeding, vaginal hematoma and wound hematoma). A poor fetal outcome was defined as any pregnancy loss (miscarriage or termination of pregnancy), stillbirth, neonatal death, fetal abnormality, Apgar score of $<7$ at 5 minutes, or admission to the neonatal unit ${ }^{(2)}$.

Commonly used risk scores to detect complications during pregnancy in women with cardiac disease are the Cardiac Disease in Pregnancy (CARPREG), Zwangerschap bij Aangeboren Hartafwijkingen (ZAHARA) risk scores, and World Health Organization (WHO) mater (recommended in 2018 European Society of Cardiology [ESC] guidelines) ${ }^{(3)}$.

Prosthetic valves are excluded for risk stratification in CAPREG score whereas they are incorporated as an indicator of maternal cardiovascular events in ZAHARA system. The modified WHO maternal cardiovascular risk score classifies mechanical valves class III risk (maternal cardiac illness rate of 19-27\%) and bioprosthetic valve as class II-III risk (maternal cardiac illness rate of $10-19 \%)^{(4)}$.

This article is an open access article distributed under the terms and conditions of the Creative Commons Attribution (CC BY-SA) license (http://creativecommons.org/licenses/by/4.0/) 
Mechanical valves have great durability and hemodynamic profile. Mechanical prosthetic valves, nonetheless, are thrombogenic and require lifelong anticoagulation to prevent thromboembolic complications. Three anticoagulant regimens are commonly used in pregnancy: warfarin throughout, low-molecular-weight heparin (LMWH) throughout, or LMWH in the first trimester, then warfarin until the mid-third trimester, switching back to LMWH or unfractionated heparin before delivery ${ }^{(5)}$.

Bioprosthetic valves (homografts, heterografts, or autografts) are much less thrombogenic than mechanical valves. However, they do obviate the need of long-term anticoagulation, thereby resulting in better maternal and fetal results, as seen in ROPAC (Registry of Pregnancy and Cardiac Disease). Women with well-functioning bioprosthetic cardiac valves and those who do not have other cardiac risk factors often have safe pregnancies. Notwithstanding, there remains a substantial danger of structural deterioration in bioprosthetic valves in young women ${ }^{(6)}$.

Warfarin is thought to have the least danger of maternal complications but is associated with higher rates of fetal complications and demise. "Warfarin embryopathy" is a known complication of warfarin treatment during pregnancy, mainly between the 6th and 12th weeks of pregnancy. It is described by nasal hypoplasia, low birth weight, slower growth, mental retardation, malformed bones, cartilage and joints, stippled epiphyses, deafness, and small head size. The teratogenicity of warfarin is discovered to be somewhat dose dependent, with more frequent and fatal fetal malformations occurring when warfarin doses of greater than $5 \mathrm{mg} /$ day are given ${ }^{(7)}$.

ESC 2018 guideline says that the utilization of vitamin K Antagonists (VKAs) (warfarin) throughout pregnancy, under strict international normalized ratio (INR) control, is the most secure routine to prevent valve thrombosis ${ }^{(7)}$.

The aim of this study was to observe maternal and fetal outcomes in pregnant women with heart valve replacement on used different anticoagulant regimens and to plan a strategy to improve fetal and maternal outcomes.

\section{PATIENTS AND METHODS}

An observational study was done in Sohag University Hospital, 20 cases recruited in Department of Obstetrics and Gynecology during the period from April 2019 to October 2019.

\section{Inclusion criteria:}

- Pregnant women with heart valve replacement.

- Either single or double valve replacement.

- Using warfarin or LMWH therapy.

- Either primigravidas or multiparas.
- Underwent CS or vaginal deliveries.

All cases were exposed to the following:

- Thorough history taking.

- Complete physical examination (general and obstetric).

- Obstetric US.

- Investigations (echocardiography, abdominal ultrasound, prothrombin time, concernation, INR, $\mathrm{CBC}$, blood urea and creatinine.

\section{Pregnancy outcome:}

- The primary maternal outcome was maternal mortality.

- The primary fetal outcome was any pregnancy loss including miscarriage, termination of pregnancy and perinatal mortality (stillbirth or neonatal mortality). Stillbirth is defined as fetal death in utero $\geq 28$ weeks' gestation and neonatal mortality as death in the first 28 days of extrauterine life.

- The secondary outcomes were adverse maternal outcomes (thromboembolic events, obstetric hemorrhage, cardiovascular compromise, new maternal arrhythmia, infective endocarditis, myocardial infarction and pregnancy hypertension) and adverse birth outcomes [small for gestational age (SGA), low birth weight (LBW), preterm birth, congenital malformation and infant admission to Neonatal Intensive Care Unit (NICU)].

\section{Ethical approval:}

The study was approved by the Ethics Board of Sohag University and an informed written consent was taken from each participant in the study.

\section{Statistical analysis:}

Statistical analysis was done by SPSS version 25 (IBM@), Chicago, IL, USA). Quantitative parametric data were introduced as mean, standard deviation (SD) and range. Quantitative nonparametric data were presented as median and range. Qualitative data were presented as number and percent and were compared by chi-square $\left(\mathrm{X}^{2}\right)$ or Fisher's Exact test. A two-tailed $\mathrm{P}$ value $\leq 0.05$ was considered statistically significant.

\section{RESULTS}

Table (1) showed that the mean age of the study women was around 28 years, with a range from 18 to 38 years old. Around two thirds of the cases were from rural areas. Regarding parity, one third of the cases ( 7 cases, $35 \%)$ were nulliparous, with a mean number of previous deliveries of 2.3. The gestational age showed a wide variation, with a mean of 29 and standard deviation of more than 10 weeks. 
4 cases had twins (20\%) and 8 had previous CS (40\%). Regarding the preexisting chronic diseases, $20 \%$ were passive smokers, $15 \%$ hypertensive, $10 \%$ diabetic and none of them was active smoker. Previous cardiac intervention was recorded in around half of the cases ( 9 cases, $45 \%$ ).

Table (1): Baseline demographic and clinical characteristics of the study population

\begin{tabular}{|c|c|c|}
\hline \multicolumn{2}{|r|}{ Item } & Value \\
\hline \multirow[t]{2}{*}{ Age (years) } & Mean \pm SD & $\begin{array}{c}27.9 \pm \\
5.6\end{array}$ \\
\hline & Median(range) & $\begin{array}{c}26.5 \\
(18-38)\end{array}$ \\
\hline \multirow[t]{2}{*}{ Residence } & Urban & $7(35 \%)$ \\
\hline & Rural & $\begin{array}{c}13 \\
(65 \%)\end{array}$ \\
\hline \multirow[t]{3}{*}{ Parity } & Nulliparous; n (\%) & $7(35 \%)$ \\
\hline & $\begin{array}{l}\text { No of previous deliveries } \\
(\text { mean } \pm \text { SD) }\end{array}$ & $\begin{array}{l}2.3 \pm \\
2.9\end{array}$ \\
\hline & $\begin{array}{l}\text { No of previous abortions } \\
(\text { mean } \pm \text { SD) }\end{array}$ & $\begin{array}{l}0.6 \pm \\
1.2\end{array}$ \\
\hline \multirow{3}{*}{$\begin{array}{l}\text { Gestational } \\
\text { and } \\
\text { obstetric } \\
\text { data }\end{array}$} & $\begin{array}{l}\text { Gestational age (mean } \pm \\
\text { SD) }\end{array}$ & $\begin{array}{c}28.9 \pm \\
10.6\end{array}$ \\
\hline & Twin pregnancy; n (\%) & $4(20 \%)$ \\
\hline & Previous CS; n (\%) & $8(40 \%)$ \\
\hline \multirow{4}{*}{$\begin{array}{l}\text { Pre-existing } \\
\text { disorders or } \\
\text { risk factors }\end{array}$} & Hypertension; n (\%) & $3(15 \%)$ \\
\hline & Diabetes mellitus; n (\%) & $2(10 \%)$ \\
\hline & Current smokers; n (\%) & $0(0 \%)$ \\
\hline & Passive smokers; n (\%) & $4(20 \%)$ \\
\hline $\begin{array}{l}\text { Previous } \\
\text { cardiac } \\
\text { intervention }\end{array}$ & No (\%) & $9(45 \%)$ \\
\hline
\end{tabular}

Table (2) showed that the majority of the cases were New York Heart Association (NYHA) class I (75\%), followed by class II (20\%) and only one case had NYHA class III $(5 \%)$. None of the cases had NYHA class IV. Clinical signs of heart failure were seen in $20 \%$ of the cases, and liver ventricular hypertension in $15 \%$ of the cases. AF before pregnancy was recorded in $10 \%$ of the cases. Regarding previous medications, beta-blockers and anti-diabetics were seen in $15 \%$ of the cases and each of anti-arrhythmias and ACE inhibitors were seen in $10 \%$ of the cases.
Table (2): Baseline cardiac data of study population

\begin{tabular}{|l|c|c|}
\hline \multicolumn{2}{|c|}{ Item } & Value \\
\hline \multirow{2}{*}{$\begin{array}{l}\text { NYHA functional } \\
\text { class }\end{array}$} & I & $15(75 \%)$ \\
\cline { 2 - 3 } & II & $4(20 \%)$ \\
\cline { 2 - 3 } & III & $1(5 \%)$ \\
\cline { 2 - 3 } Clinical signs of HF & IV & 0 \\
\hline $\begin{array}{l}\text { Left ventricular } \\
\text { hypertension }\end{array}$ & N0 (\%) & $4(20 \%)$ \\
\hline AF before pregnancy & N0 (\%) & $2(5 \%)$ \\
\hline $\begin{array}{l}\text { Previous } \\
\text { medications }\end{array}$ & Beta blockers & $3(15 \%)$ \\
\cline { 2 - 3 } & Anti-arrhythmic & $2(10 \%)$ \\
\cline { 2 - 3 } & ACE inhibitors & $2(10 \%)$ \\
\cline { 2 - 3 } & Diuretics & $3(15 \%)$ \\
\hline
\end{tabular}

Table (3) showed that the vast majority of the cases had mitral valve replaced; either alone in $75 \%$ of the cases or combined with aortic valve in $10 \%$ of them, while aortic valve was replaced alone in only $15 \%$ of the cases. Regarding the obstetric intervention, CS was done for $40 \%$ of the cases, followed by vaginal delivery in $35 \%$ of them (combined with IUC in $25 \%$ of the cases), evacuation in $20 \%$ (combined with IUC in $10 \%$ of the cases) and hysterotomy in one case (5\%).

Table (3): Cardiac and obstetric intervention data of the study population

\begin{tabular}{|l|c|c|}
\hline \multicolumn{2}{|c|}{ Item } & Value \\
\hline Valve replaced & Mitral valve & $15(75 \%)$ \\
\cline { 2 - 3 } & Aortic valve & $3(15 \%)$ \\
\cline { 2 - 3 } & $\begin{array}{c}\text { Mitral + aortic } \\
\text { valves }\end{array}$ & $2(10 \%)$ \\
\hline \multirow{5}{*}{$\begin{array}{l}\text { Obstetric } \\
\text { intervention }\end{array}$} & Vaginal delivery & $2(10 \%)$ \\
\cline { 2 - 3 } & $\begin{array}{c}\text { IUC + vaginal } \\
\text { delivery }\end{array}$ & $5(25 \%)$ \\
\cline { 2 - 3 } & CS & $8(40 \%)$ \\
\cline { 2 - 3 } & Evacuation & $3(15 \%)$ \\
\cline { 2 - 3 } & $\begin{array}{c}\text { IUC then } \\
\text { evacuation }\end{array}$ & $1(5 \%)$ \\
\cline { 2 - 3 } & Hysterotomy & $1(5 \%)$ \\
\hline
\end{tabular}

Table (4) showed that the majority of cases were admitted (85\%), and around one third needed ICU admission (7 cases, 35\%) from whom 6 cases needed ICU due to cardiac causes. Hemorrhagic complications were seen in $25 \%$ of the cases, followed by thrombosis and rapid AF (10\% each), then heart failure and supraventricular arrhythmias (5\% each). Regarding the offspring outcome, miscarriage before the $24^{\text {th }}$ week occurred in $30 \%$ of the cases and IUFD in one case (5\%). Preterm labor before $37^{\text {th }}$ week occurred in 3 cases $(15 \%)$. 
Table (4): Outcome of pregnancy until the week 1 postpartum

\begin{tabular}{|c|c|c|}
\hline \multicolumn{2}{|r|}{ Item } & \multirow{2}{*}{$\frac{\text { Value }}{0}$} \\
\hline Maternal mortality & No & \\
\hline \multirow{3}{*}{ Maternal morbidity } & Maternal admission & $17(85 \%)$ \\
\hline & Maternal ICU admission & $7(35 \%)$ \\
\hline & Maternal admission due to cardiac cause & $6(30 \%)$ \\
\hline \multirow[t]{8}{*}{ Cardiac complications } & Heart failure & $1(5 \%)$ \\
\hline & Endocarditis & 0 \\
\hline & Supraventricular arrhythmia & $1(5 \%)$ \\
\hline & Ventricular arrhythmia & 0 \\
\hline & Thrombotic complications & $2(10 \%)$ \\
\hline & Mechanical valve thrombosis & 0 \\
\hline & Rapid AF & $2(10 \%)$ \\
\hline & Hemorrhagic complications & $5(25 \%)$ \\
\hline \multirow[t]{2}{*}{ Obstetric outcome } & Pregnancy induced hypertension & 0 \\
\hline & $\mathrm{CS}$ & $8(40 \%)$ \\
\hline \multirow[t]{8}{*}{ Offspring outcome } & $\begin{array}{c}\text { Live birth } \\
\text { Miscarriage }<24 \text { weeks }\end{array}$ & $\begin{array}{l}13(65 \%) \\
6(30 \%)\end{array}$ \\
\hline & Fatal mortality $>24$ weeks & $1(5 \%)$ \\
\hline & Therapeutic abortion & 0 \\
\hline & Preterm labor $<37$ weeks & $3(15 \%)$ \\
\hline & APGAR score; mean \pm SD & $7.6 \pm 0.5$ \\
\hline & APGAR score; median(range) & $8(7-8)$ \\
\hline & Birth weight $(\mathrm{gm})$; mean \pm SD & $2530 \pm 267$ \\
\hline & Birth weight(gm); median(range) & $\begin{array}{c}2500 \\
(2200-2900)\end{array}$ \\
\hline
\end{tabular}

Figure (1) showed that before 14 weeks of gestation, most of the cases used heparin either UFH or LMWH, with only $35 \%$ used vitamin $\mathrm{K}$ antagonists. This was opposite in later stages of pregnancy, where most of the cases (80\%) used VKA. Lastly, in the peripartum period, $70 \%$ of the cases used UFD, $10 \%$ used LMWH, while only one case used VKA and 3 cases did not receive anything (15\%).

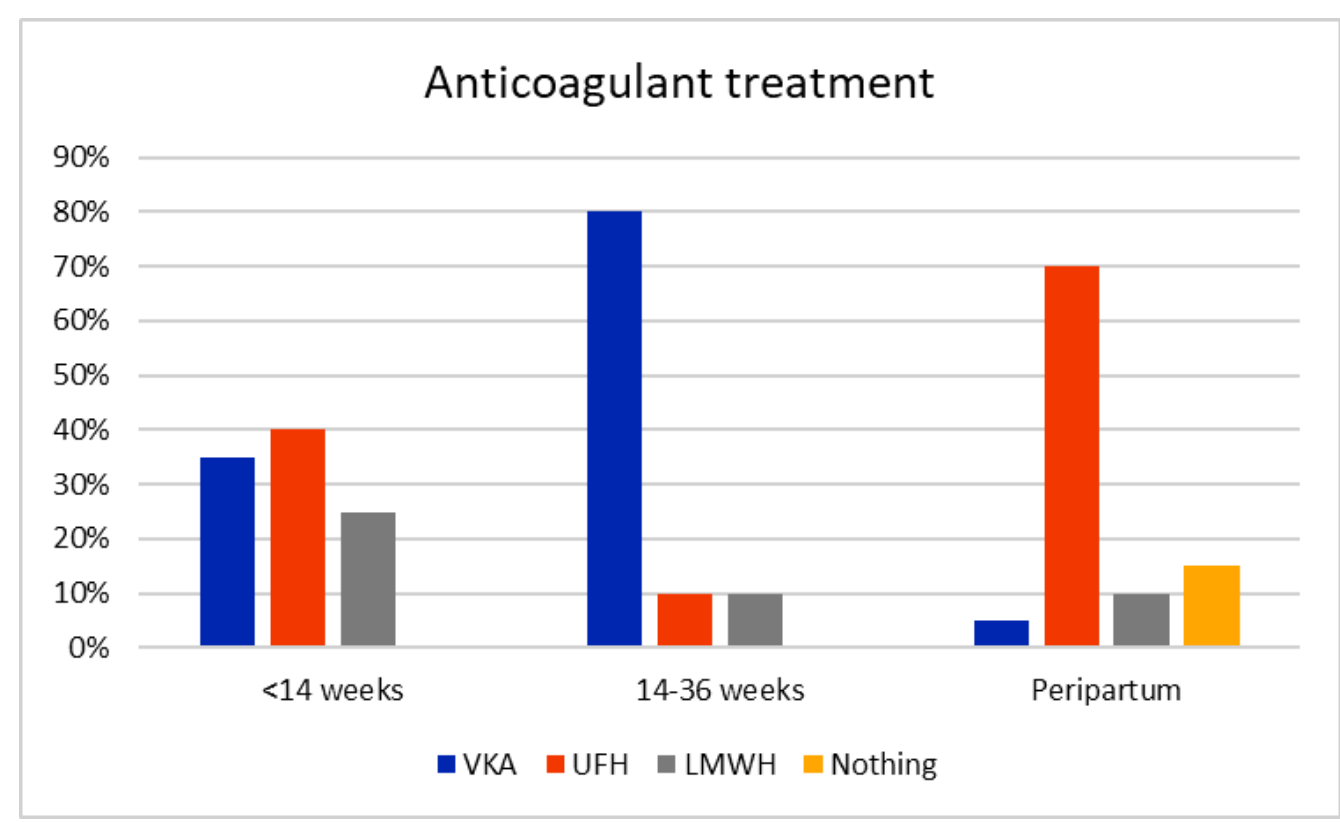

Figure (1): Anticoagulant therapy

Incidence of missed abortion was greater in patients received heparin than who received VKA $(53.8 \%$, $28.6 \%$ respectively). IUFD occurred in $14.3 \%$ of patients received VKA (figure 2 ). 


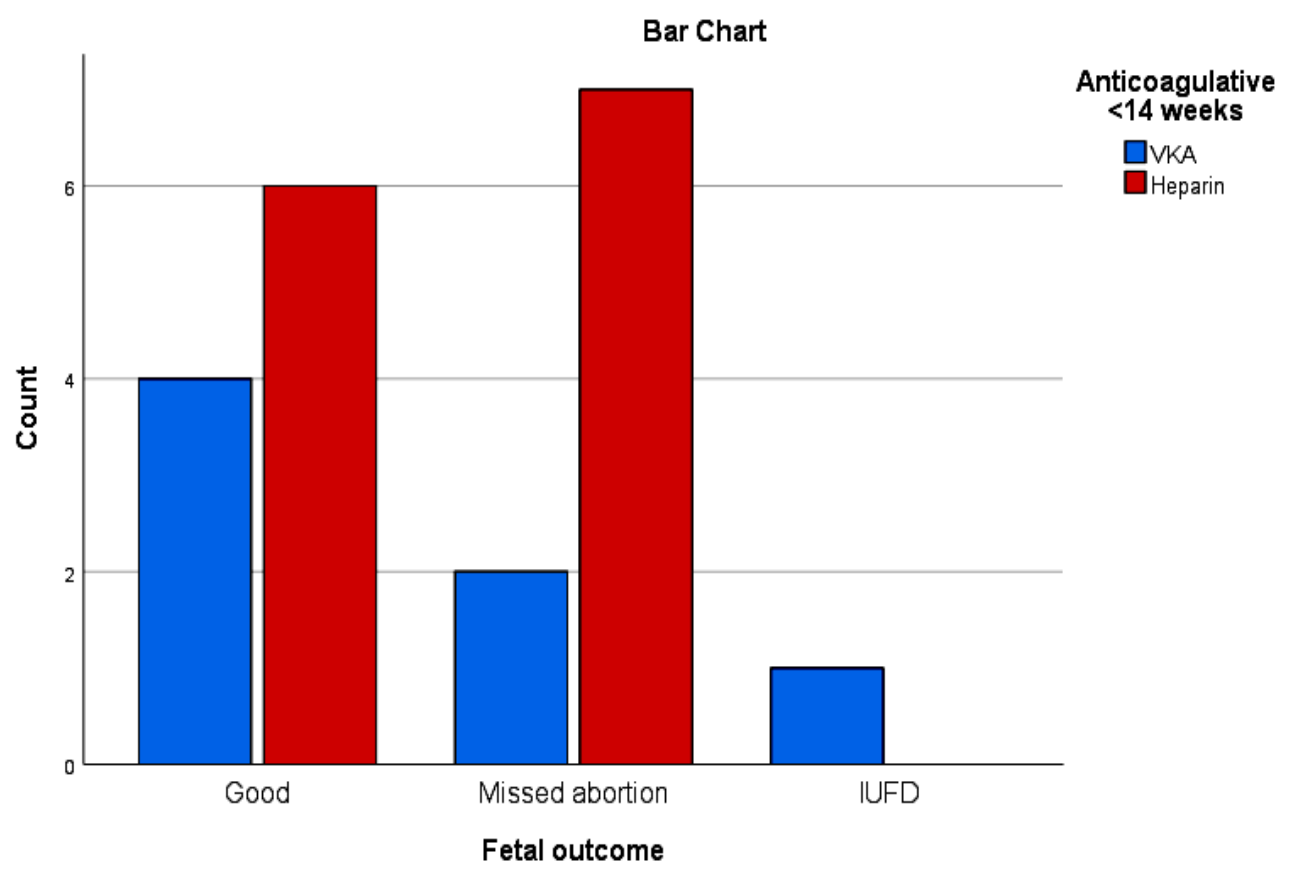

Figure (2): Anticoagulant therapy versus fetal outcome

The incidence of postpartum hemorrhage was greater in patients who received VKA daily than in patients who received heparin with no significant difference (figure 3 ).

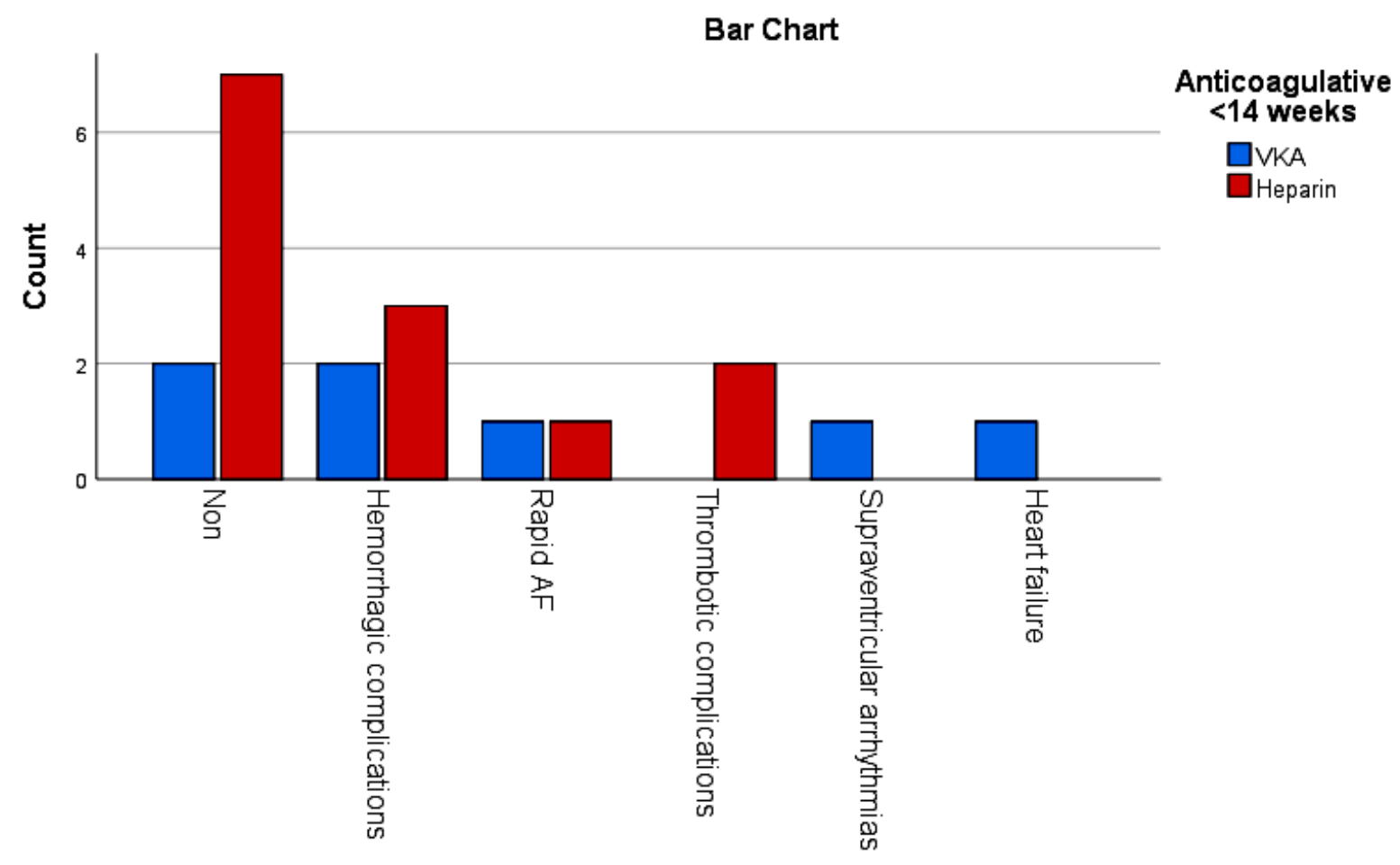

\section{Cardiac}

Figure (3): Maternal complications according to Anticoagulant therapy.

Hemorrhage was more common with MVR. Postpartum hemorrhage was more common also in patients with aortic valve prostheses than in patients with mitral valve and aortic valve prostheses (figure 4). 


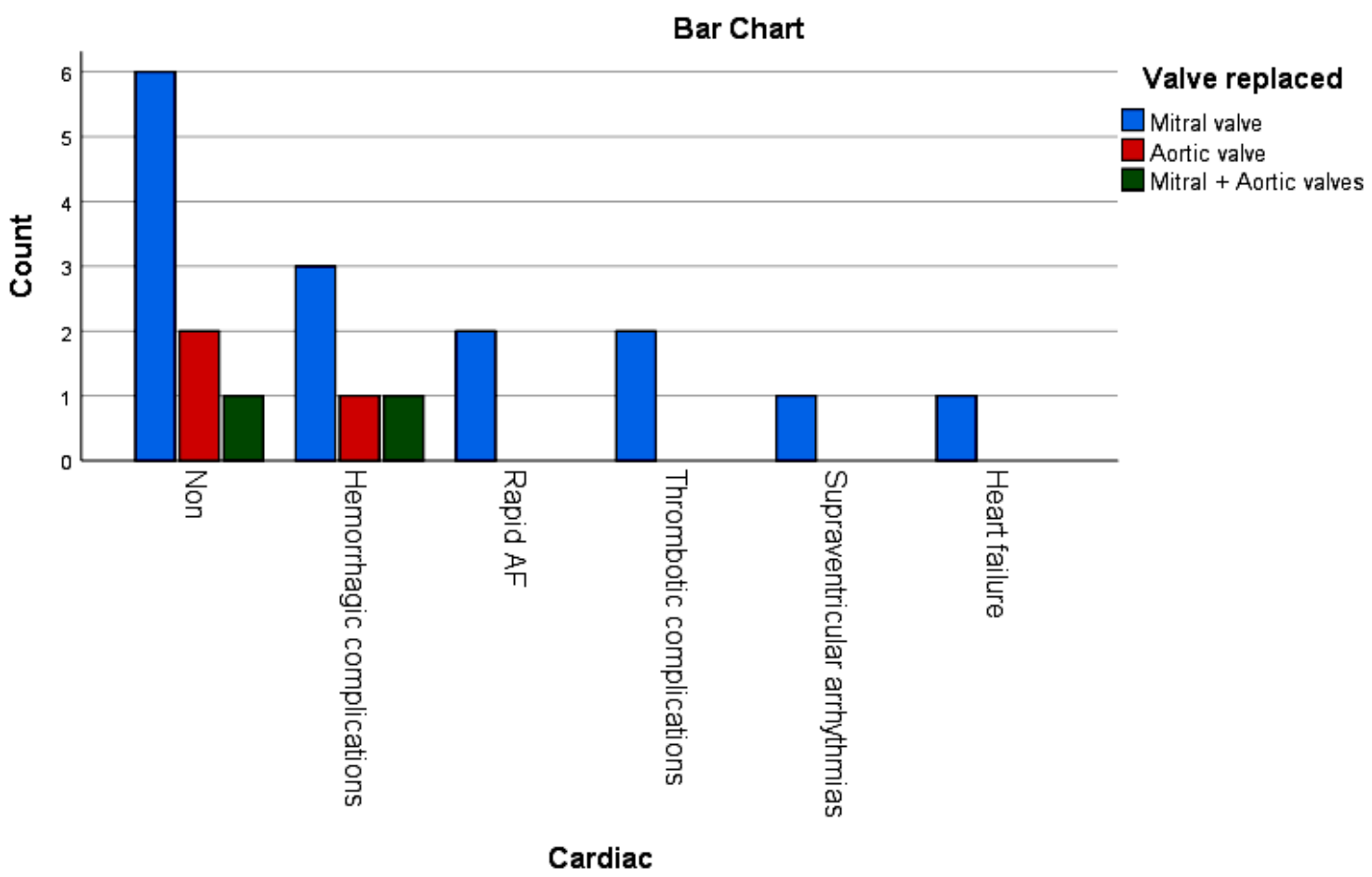

Figure (4): Maternal complications according to the site of the replaced valve.

\section{DISCUSSION}

Physiologic changes are seen in pregnancy to enhance fetal growth and development. The major cardiovascular hemodynamic changes found in pregnancy include increased cardiac output, expanded blood volume, and reduced systemic vascular resistance and blood pressure. Increased preload (due to the expansion of the blood volume), decreased afterload (due to the decreased systemic vascular resistance), and increased maternal heart rate all lead to increased cardiac output and workload (1).

The presence of heart disease seems to increase the danger of obstetric troubles. In a retrospective study of 112 pregnancies in women with congenital heart disease, Ouyang et al. (8) reported a $32.6 \%$ rate of adverse obstetric results. Preterm delivery and postpartum hemorrhage were the most recurrent complications seen. Preterm delivery was due to preterm premature rupture of membranes and indicated deliveries.

The mean age of the study population was around 28 years, ranging from 18 to 38 years. Around two thirds of the cases lived in rural areas. Regarding parity, one third of the cases ( 7 cases, $35 \%$ ) were nulliparous, with a mean number of previous deliveries of 2.3. The gestational age showed a wide variation, with a mean of 29 weeks and standard deviation of more than 10 weeks. 4 cases had twins (20\%) and 8 had previous CS (40\%). Regarding the preexisting chronic illness, $20 \%$ were passive smokers, $15 \%$ hypertensive, $10 \%$ diabetic and none of them was active smoker. Previous cardiac intervention was recorded in around half of the cases ( 9 cases, $45 \%$ ).

The majority of the cases in our study were NYHA class I (75\%), followed by class II (20\%) and only one case had NYHA class III (5\%). None of the cases had NYHA class IV. Clinical signs of heart failure were seen in $20 \%$ of the cases, and superimposed by hypertension in $15 \%$ of the cases. $\mathrm{AF}$ before pregnancy was recorded in $10 \%$ of the cases. Regarding previous drugs, beta-blockers and anti-diabetics were seen in $15 \%$ of the cases and each of anti-arrhythmias and ACE inhibitors were seen in $10 \%$ of the cases.

Most of the cases had mitral valve replaced either alone in $75 \%$ of the cases or combined with aortic valve in $10 \%$ of them, while aortic valve was replaced alone in only $15 \%$ of the cases. This is similar to Ayad et al. ${ }^{\left({ }^{(9)}\right.}$ as the most common valve replaced in their study was the mitral valve in 60 patients (60\%), followed by AVR in 22 patients (22\%) and DVR in 18 patients (18\%). Tounsi $\boldsymbol{e t}$ al. (10) identified 86 pregnancies that included 57 women with PHVs. There were 34 cases (59.65\%) of MVR, 7 cases $(12.28 \%)$ of AVR, and 16 cases $(28.07 \%)$ of DVR.

Regarding the obstetric intervention, CS was done for $40 \%$ of the cases, followed by vaginal delivery in $35 \%$ of them (combined with IUC in $25 \%$ of the cases), evacuation in $20 \%$ (combined with IUC 
in $10 \%$ of the cases) and hysterotomy in one case $(5 \%)$.

We have no maternal mortality. Regarding maternal illness, the majority of the cases were admitted (85\%), and around one third needed ICU admission ( 7 cases, 35\%) from whom 6 cases needed ICU due to cardiac causes. Regarding the cardiac complications, hemorrhagic complications were seen in $25 \%$ of the cases, followed by thrombosis and rapid AF (10\% each), then heart failure and supraventricular arrhythmias (5\% each). None of our cases experienced endocarditis, ventricular arrhythmias, mechanical valve thrombosis or pregnancy-induced hypertension. On the other hand, in a large contemporary study of 212 women with an MHV, van Hagen et al. (11) revealed a maternal mortality of $1.4 \%$. Furthermore, valve thrombosis and hemorrhagic complications occurred in $4.7 \%$ and $23.1 \%$ of pregnancies respectively. Compared to our results, the incidence of maternal mortality was higher and that of hemorrhagic complications and incidence of valve thrombosis were lower. Sillesen $\boldsymbol{e t}$ al. (12) announced two maternal fatalities, both of which occurred in women with mechanical aortic prostheses. The death of a 26-year-old woman was due to hemorrhage, while the other patient died of rapidly progressive and irreversible left-heart failure at 27 weeks of gestation.

Regarding the offspring result, miscarriage before the $24^{\text {th }}$ week occurred in $30 \%$ of the cases and IUFD in one case $(5 \%)$. Preterm labor before $37^{\text {th }}$ week occurred in 3 cases $(15 \%)$ but none of the cases required therapeutic abortion. The Apgar score ranged from 7 to 8 among the living babies, with a mean birth weight of 2530 grams. Ayad et al. (9) announced that in 52 pregnancies (52\%) ended in healthy live births and 29 terminated in abortion (20 patients [33.3\%] had MVR, 7 patients [31.8\%] had AVR, and 2 patients [11.1\%] had DVR). One patient had a therapeutic abortion due to increased maternal age at 43 years, with a history of ischemic heart disease (IHD) and debilitated left ventricle systolic function. Fetal deaths occurred in 16 pregnancies, of which 14 were in women with MVRs. Perinatal deaths occurred in three patients. The first case was due to intracerebral bleeding, while the remaining two cases were due to prematurity. Two infants were born with congenital malformations. Atrial septal defect and tongue-tie were found in one newborn, while the other newborn had cyanotic heart disease. Warfarin embryopathy was not detected in any case.

In our study, before 14 weeks of pregnancy, most of the cases used heparin either UFH or LMWH, with only $35 \%$ used vitamin $\mathrm{K}$ antagonists. This was opposited in later stages of pregnancy, where most of the cases $(80 \%)$ used VKA. Lastly, in the peripartum period, $70 \%$ of the cases used UFD, $10 \%$ used LMWH, while only one case used VKA and 3 cases did not get anything (15\%). Incidence of missed abortion was more prominent in patients received heparin than who received VKA $(53.8 \%, 28.6 \%$ respectively). IUFD occurred in $14.3 \%$ of patients received VKA.

The incidence of postpartum hemorrhage was greater in patients who received VKA daily than in patients who received heparin with no significant difference. Postpartum hemorrhage was more common with MVR and aortic valve prostheses than in patients with combined mitral valve and aortic valve prostheses.

Mazibuko et al. (13) found no inherent fetal anomalies in $29(50 \%)$ patients on $>5 \mathrm{mg}$ of warfarin during the first three months of pregnancy. Furthermore, the four $(7 \%)$ cases of embryopathies occurred in women who were taking $5 \mathrm{mg}$ of warfarin daily. They reported a greater incidence of warfarin embryopathy in patients who received warfarin during the first trimester. However, not all of our patients received warfarin during the first trimester.

Our outcomes are in concordance with Tounsi et al. (10) and Samiei et al. (14), regarding the lower rate of maternal complications in women receiving anticoagulants in the first trimester. With the exception of Tounsi et al. ${ }^{(10)}$. Our results are also similar to them regarding fetal outcome in the heparin group, with live births occurring in 50-60\% of pregnancies compared to $46.2 \%$ in our study. Contrary to their results, we noted a higher rate of missed abortions (53.8\%) in women receiving heparin during the first trimester. Samiei et al. (14) reported $52 \%$ and $60.5 \%$ live births, respectively, in the group receiving warfarin during the first trimester Similarly, data from Sillesen et al. ${ }^{(12)}$ confirmed that fetal complications primarily involved increased numbers of miscarriages and growth restriction that is possibly linked to the use of vitamin $\mathrm{K}$ antagonists. However, warfarin embryopathy was only observed in a few patients on continued high dose warfarin. Data from the European Society of Cardiology ROPAC revealed that the use of vitamin $K$ antagonists compared to heparin in the first trimester was associated with a higher rate of miscarriage (28.6\% versus $9.2 \%$; $\mathrm{P}, 0.001)$ and late fetal death (11)

\section{CONCLUSION}

Patients with mechanical valves have more incidence of fetal loss and maternal complications. Warfarin was as effective as heparin in preventing thromboembolic complications and valvular malfunction in the mother and seems to have less harm on the fetal outcome. Mitral valve replacement is associated with more maternal hemorrhagic complications than aortc valve alone or double valve replacement. 


\section{REFERENCES}

1. Meah V, Cockcroft J, Backx K et al. (2016): Cardiac output and related haemodynamics during pregnancy: a series of meta-analyses. Heart, 102: 518-526.

2. Khairy P, Ouyang D, Fernandes S et al. (2006): Pregnancy outcomes in women with congenital heart disease. Circulation, 113: 517-524.

3. Drenthen W, Boersma E, Balci A et al. (2010): Predictors of pregnancy complications in women with congenital heart disease. European Heart Journal, 31: 2124-2132.

4. Regitz-Zagrosek V, Blomstrom Lundqvist C, Borghi C et al. (2011): European Society of Gynecology (ESG), Association for European Paediatric Cardiology (AEPC), German Society for Gender Medicine (DGesGM). ESC Guidelines on the management of cardiovascular diseases during pregnancy: the Task Force on the Management of Cardiovascular Diseases during Pregnancy of the European Society of Cardiology (ESC). Eur Heart J., 32: 3147-97.

5. D'Souza R, Ostro J, Shah $P$ et al. (2017): Anticoagulation for pregnant women with mechanical heart valves: a systematic review and meta-analysis. European Heart Journal, 38: 1509-1516.

6. Popelová J, Zatočil T, Vavera $Z$ et al. (2012): Mechanical heart valve prosthesis in pregnancymulticenter retrospective observational study. Cor et Vasa, 54: 217-222.

7. Pradhan A, Gupta V, Vishwakarma P (2018): Prosthetic Heart Valves and Pregnancy: Challenges and
Solutions. Indian Journal of Cardiovascular Disease in Women. WINCARS, 3: 115-125.

8. Ouyang D, Khairy P, Fernandes S et al. (2009): Obstetric outcomes in pregnant women with congenital heart disease. Int J Cardiol., 144: 195-9.

9. Ayad S, Hassanein M, Mohamed E et al. (2016): Maternal and Fetal Outcomes in Pregnant Women with a Prosthetic Mechanical Heart Valve. Clinical Medicine Insights: Cardiology, 10: 36740-5.

10. Tounsi A, Abid D, Louati D et al. (2014): Anticoagulation in pregnant women with mechanical heart valve prostheses: 25-year experience at a tertiary care hospital in a developing country. World Journal of Cardiovascular Diseases, 4: 287-93.

11.van Hagen I, Roos-Hesselink J, Ruys T et al. (2015): Pregnancy in women with a mechanical heart valve: data of the European Society of Cardiology Registry of Pregnancy and Cardiac Disease (ROPAC). Circulation, 132: 132-142.

12.Sillesen M, Hjortdal V, Vejlstrup N et al. (2011): Pregnancy with prosthetic heart valves-30 years' nationwide experience in Denmark. European Journal of Cardio-Thoracic Surgery, 40: 448-454.

13. Mazibuko B, Ramnarain H, Moodley J (2012): An audit of pregnant women with prosthetic heart valves at a tertiary hospital in South Africa: a five-year experience. Cardiovasc J Afr., 23: 216-21.

14. Samiei N, Kashfi F, Khamoushi A et al. (2012): Pregnancy outcome after mechanical mitral valve replacement: a prospective study. J Tehran Heart Cent., 7: $117-20$. 